\title{
The effect of peripheral neuropathy on daily life activities in patients receiving chemotherapy
}

\author{
Ezgi Bicakci*1, Meftun Akgün² \\ ${ }^{1}$ Istanbul Sultan 2.Abdülhamid Han, Training and Research Hospital, Turkey \\ ${ }^{2}$ Üsküdar University, Faculty of Health Siences, Turkey
}

Received: July 8, 2020

DOI: $10.5430 /$ cns.v8n3p45
Accepted: September 8, 2020

Online Published: September 17, 2020

\begin{abstract}
Objective: The aim of this study is to determine the relationship between pain and pain related factors associated with peripheral neuropathy and daily life activities in patients receiving chemotherapy.

Methods: The study used a descriptive and cross-sectional design to examine 80 patients who came to the outpatient chemotherapy unit of two university hospitals to receive chemotherapy drugs such as taxane, platinum analogs and vinca alkaloids. The data were collected by using face-to-face interview method through "General Information Form", "S-LANSS Pain Scale" that is a bedside test for distinctive diagnosis of neuropathic pain and "Health Assessment Questionnaire (HAQ)" which is a scale prepared by the researcher and measures daily activities to evaluate physical disability.

Results: In the group with neuropathic pain, HAQ scores $(p=.003 ; p<.01)$ and S-LANSS scores $(p=.005 ; p<.01)$ of the patients who did not have hand-foot complaints prior to the treatment but experienced hand-foot discomfort with the beginning of chemotherapy treatment, were found to be statistically significantly higher. There was a statistically significant positive relation between HAQ score and S-LANSS pain score at the level of $61.2 \%(r=0.612 ; p=.001 ; p<.01)$.

Conclusions: It was concluded that the symptoms of Chemotherapy-Induced Peripheral Neuropathy (CIPN) and related pain and pain-related factors negatively affect the level of doing daily life activities.
\end{abstract}

Key Words: Chemotherapy, Peripheral neuropathy, Neuropathic pain, Physical activity

\section{INTRODUCTION}

Cancer continues to be an important health problem for the world due to its mortality, burden of the disease, and everincreasing incidence. According to the World Health Organization (WHO) report, it is stated that cancer is the cause of 8.8 million people's death in 2015 globally.

Although cancer treatment is determined according to the histological structure of the tumor, stage of the disease and metastasis, the most common cancer treatments are surgery, radiotherapy, immunotherapy and chemotherapy. Some side effects may develop during chemotherapy treatment and the severity and type of these side effects may vary from person to person, and may lead to reducing the dose of the treatment or discontinuation of the treatment by affecting the patient's quality of life. ${ }^{[1-4]}$

One of the concerns that should be considered when using chemotherapy drugs is drug toxicity. Drug toxicity causes cardiotoxicity, neurotoxicity, eye, lung, hematologic, skin Turkey.

*Correspondence: Ezgi Bicakci; Email: ezgibicakci88@ gmail.com; Address: İstanbul Sultan 2.Abdülhamid Han, Training and Research Hospital, 
and renal toxicity, but also increases morbidity and mortality rate. ${ }^{[5]}$ Also, neurotoxicity is a significant dose-limiting side effect that leads to discontinuation or reduction of drug therapy. In the literature, the peripheral nervous system has been reported to be more sensitive to the neurological effects of chemotherapy compared to the central nervous system. ${ }^{[6-8]}$ Neurotoxicity is more common in patients receiving chemotherapeutic agents including platinum analogs, vinca alkaloids, taxanes, ifosfamide and methotrexate. ${ }^{[6]}$ The most common symptoms of CIPN experienced by patients are defined as burning, numbness, tingling, needling, a feeling of stinging/incision, muscular contractions and electric-shock like pain. Signs and symptoms of neuropathy, often starts with the big toe first, reaches feet, ankles, and then legs. ${ }^{[6,9,10]}$ They may also cause weakness in the hand and foot muscles due to the affected motor fibers. ${ }^{[11]}$

Patients do not use the word "pain" when describing the discomfort in their hands and feet. ${ }^{[12]}$ However, Reyes-Gibby et al. state that the pain suffered by $40 \%$ of cancer patients is neuropathic pain. ${ }^{[11]}$ Painful and painless symptoms of neuropathy include numbness, loss of balance, muscle weakness, tingling, weakness, lack of coordination, short-term memory loss, loss of depth perception, concentration problem, sensitivity to cold, pain, burning, muscle aches, pinprick, sharp pain, joint pain, electric shock-like pain, fever-like pain, pressure and stabbing pain. Neuropathic pain symptoms may adversely affect daily life activities such as writing, walking, sleeping, doing housework, or exercising. ${ }^{[12]}$

It is stated in the literature that, when the side effect of the drug is encountered, changes to be made in the treatment and the supplementary therapies to be added are determined to be of great significance. Also, the evaluation of these symptoms, which adversely affect the treatment process of the cancer, have been found to be significant in terms of enhancing the life quality of patients by early detection of symptoms, ensuring the continuation of the treatment, and preventing possible psychological problems that may arise. Training and awareness should be established for neuropathy, evaluation of peripheral neuropathy with toxicity assessment scales, early detection and prevention of symptoms by continuous observation and recording, and pharmacological and non-pharmacological methods should be evaluated. Thus, peripheral neuropathy and neuropathic pain should be reported, and the quality of life of the patient should be improved by conducting interventions. ${ }^{[13-15]}$

The present study was designed to determine the relationship between pain related factors associated with peripheral neuropathy and pain with the daily life activities in patients receiving chemotherapy.

\section{METHODS}

\subsection{Type of the study}

This study was carried out between February 2017 and June 2017 in a descriptive, correlational, and cross-sectional type in the Outpatient Chemotherapy Units of the Health Sciences University Haydarpaşa Numune Training and Research Hospital and the Health Sciences University Sultan Abdülhamid Han Training and Research Hospital.

\subsection{Population and sample}

The population of the study consisted of patients who came to the Outpatient Chemotherapy Units of Haydarpaşa Numune Training and Research Hospital and Sultan Abdülhamid Training and Research Hospital Ambulatory between February 2017 and June 2017 to receive chemotherapy drugs such as taxane, platinum analogs, and vinca alkaloids.

The sample consisted of patients who were aged 18 or over, continued chemotherapy treatment, had already received at least two cures (cycle- one chemotherapy followed by one rest period) of chemotherapy, had been receiving at least one of the drug groups including taxane class compounds, platinum-based compounds, or vinca alkaloids as chemotherapy agents, had no communication problems, submitted consent for participation in the study, and were oriented to time and place. A power analysis was conducted using the G*Power (v3.1.7) software package to determine the sample size. In the literature, the rate of neuropathic pain observed in patients with cancer was determined to vary between 27 and $30 \%$. For this reason, assuming that we might obtain a $28 \%$ rate, the sample size considered to represent the population at the highest level was determined to be 80 based on $\alpha=$ 0.10 risk and $80 \%$ power.

\subsection{Data collection tools}

Data were collected using a "General Information Form", which was developed by the researcher in light of literature and expert opinion, the "S-LANSS Pain Scale", and the 'Health Assessment Questionnaire' through face-to-face interviews. Each interview lasted about 10 minutes.

\subsubsection{The general information form}

The form, designed in light of the literature by the researcher, consists of 20 questions that intend to determine the sociodemographic characteristics of the patients (age, gender, educational status, and occupation), their disease/health characteristics (smoking, alcohol consumption, time of the disease diagnosis, the length of chemotherapy treatment, medications used, existing chronic diseases, prescription/non-prescription drug use, the use of supportive treatment method, diagnosis), and the disease-related discomfort in hands and feet. 


\subsubsection{The S-LANSS pain scale}

The S-LANSS pain scale is a bedside test for the distinctive diagnosis of neuropathic pain and nociceptive pain. The scale is a modified form of the LANSS pain scale, allowing the person to self-perform the test. The Turkish adaptation study was carried out by Koç ER and Erdemoğlu AK. SLANSS was developed to distinguish whether the pain is of neuropathic (arising pain type caused by a change in a neurological structure or function, without continuous nociceptive stimulation) or nociceptive (pain type caused by stimulation of nociceptors as a result of tissue injury) origin through self-answers of the patient without clinical examination and further examination. Also, the S-LANSS pain scale includes a body map to identify painful areas, and in the pain score patients grade the worst pain that they experienced the previous week. In patients who grade the pain 12 or more at the end of the scoring, the current pain is evaluated primarily in favor of neuropathic pain. The S-LANSS pain score consists of seven items. The first five items are about the symptoms of pain. The last two items are aimed at determining whether there is the presence of allodynia and reduced pain sense. ${ }^{[16,17]}$

\subsubsection{The Health Assessment Questionnaire}

The Health Assessment Questionnaire (HAQ) was created in 1980 by Fries et al to evaluate physical disability in patients with rheumatoid arthritis. In addition to its use mostly in patients with arthritis, the form could be used in chronic diseases, as well. The questionnaire was adapted to Turkish in 2004 by Küçükdeveci A. et al. The HAQ is a scale that consists of a total of 20 items in eight sections and evaluates daily life activities. Each item is scored from 0 to 3 (0: I do it without any difficulty; 1 : I do it with some difficulty; 2: I do it with much difficulty; 3 : I am unable to do it). Scoring also includes the use of aids or devices and the help requested from another person.

The sections that form the scale include dressing and grooming, arising, eating, walking, hygiene, reach, grip, and daily activities. Each section contains two or three items. Also, each section is scored separately and the mean score of the eight sections is determined as the single HAQ score that can vary between 0 and 3. Total HAQ Score is obtained by adding the highest scores of each subgroup and dividing it into eight. The scores obtained from the HAQ incompetence index are classified as " $0-1$ " mild level of incompetence, " 1 2 " moderate level of incompetence, and " 3 " severe level of incompetence. In the scoring of the sections, the highest score obtained from the items constituting that section is accepted as the score of the section. ${ }^{[18,19]}$

\subsection{Ethics of the study}

At the outset, Ethics Committee approval of Üsküdar University, the written permission of the Ministry of Health,
Turkey Public Hospitals Institution, the permission of the authors for using the Health Assessment Questionnaire and the S-LANSS Pain Scale, and patient consent were obtained.

\subsection{Data analysis}

Data were analyzed using the NCSS (Number Cruncher Statistical System) 2007 (Kaysville, Utah, USA) software package. In addition to descriptive statistics (mean, standard deviation, median, frequency, ratio, minimum, maximum values), Student's $t$-test, Mann-Whitney $U$ test, Kruskal-Wallis test, Pearson's Chi-Square test, Fisher-Freeman-Halton test, and Fisher's Exact test, and Spearman's Correlation Analysis were employed in the analyses. Data were evaluated at $p<$ .05 significance level.

\subsection{Limitations of the study}

The results of the study were not generalizable due to the limited number of patients involved in the study from two institutions, which was accepted as the limitation of the study.

\section{RESULTS}

In this study conducted to investigate the relationship of peripheral neuropathy-related pain with daily life activities in patients receiving chemotherapy, the neuropathic pain and individual characteristics of the patients are shown in Table 1.

Of the 80 patients participating in the study, 58 (72.5\%) were found to develop neuropathic pain. Also, $72.5 \%(\mathrm{n}=58)$ of the patients in the neuropathic pain group were in the 39-79 age range, and there was no statistically significant difference between the groups in terms of age, gender, level of education, type of chemotherapy drugs, and the number of cures.

While there was no significant difference between Total HAQ scores and gender, Total HAQ score was observed to be significantly higher in patients with primary or lower education $(p<.05)($ see Table 1$)$

In the study, $10 \%(\mathrm{n}=8)$ of the patients were found to be smoking, 3.7\% $(\mathrm{n}=3)$ used alcohol, 38.8\% $(\mathrm{n}=31)$ had hypertension, $31.3 \%(\mathrm{n}=25)$ had diabetes, $3.8 \%(\mathrm{n}=3)$ had neurological diseases, and $2.5 \%(n=2)$ had renal disease.

As for the chemotherapy drug of the patients, $47.5 \%(\mathrm{n}=$ 38) were receiving platinum, $35.0 \%(\mathrm{n}=28)$ taxane, $3.7 \%$ $(\mathrm{n}=3)$ vinca, $8.8 \%(\mathrm{n}=7)$ taxane + platinum, $3.7 \%(\mathrm{n}=$ 3) platinum + vinca, and $1.3 \%(\mathrm{n}=1)$ taxane followed by vinca class of drugs. Besides, the number of cures given to the patients was as follows: $16.3 \%(\mathrm{n}=13), 2$ cures; $15.0 \%$ $(\mathrm{n}=12), 5$ cures; $15.0 \%(\mathrm{n}=12), 6$ cures; and $26.3 \%(\mathrm{n}=$ 21), 7 or more cures. 
Table 1. Comparison of the patinets characteristics according to observation of neuropathic pain and total HAQ score $(\mathrm{n}=$ 80)

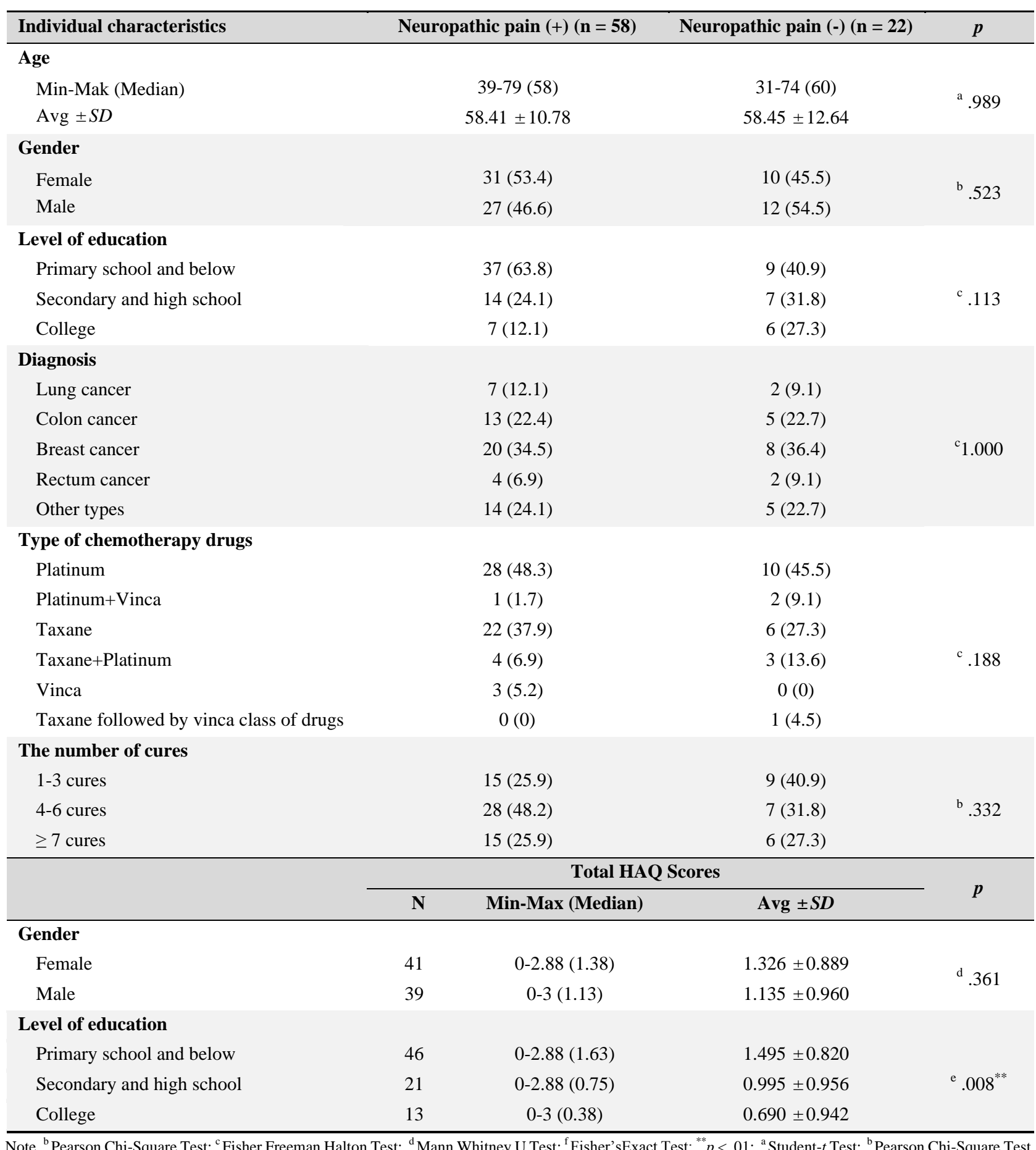

When the distribution of chemotherapy-induced discomfort in hands and feet of the patients by the chemotherapy drug classes received was examined in the study, the following problems were observed: sensitivity to cold in 24 patients and tingling in 20 patients receiving platinum; numbness in 2 patients receiving platinum + vinca; numbness in 14 patients, tingling in 13 patients, and burning in 12 patients receiving taxane; pain in joints in 4 patients and numbness in 4 patients using taxane + platinum; reduced sensitivity in 3 patients receiving vinca; and numbness in one patient receiving taxane followed by vinca (see Table 2). 
Table 2. The range of the observation of the discomfort in hands and feet according to the the type of chemotherapeutic medicine applied $(\mathrm{n}=80)$

\begin{tabular}{|c|c|c|c|c|c|c|c|}
\hline $\begin{array}{l}\text { ×Discomfort in } \\
\text { hands and feet }\end{array}$ & $\begin{array}{l}\text { Platinum } \\
\text { n }(\%)\end{array}$ & $\begin{array}{c}\text { Platinum+Vinca } \\
\text { n }(\%)\end{array}$ & $\begin{array}{c}\text { Taxane } \\
\text { n (\%) }\end{array}$ & $\begin{array}{c}\text { Taxane+Platinum } \\
\text { n }(\%)\end{array}$ & $\begin{array}{l}\text { Vinca } \\
\text { n }(\%)\end{array}$ & $\begin{array}{c}\text { Taxane followed by } \\
\text { vinca class of drugs } n \\
(\%)\end{array}$ & ${ }^{\mathrm{c}} p$ \\
\hline Tingling & $20(52.6)$ & $0(0)$ & $13(46.4)$ & $2(28.6)$ & $2(66.7)$ & $0(0)$ & ${ }^{\mathrm{c}} .425$ \\
\hline Burning & $11(28.9)$ & $0(0)$ & $12(42.9)$ & $2(28.6)$ & $0(0)$ & $0(0)$ & ${ }^{\mathrm{c}} .556$ \\
\hline Loss of balance & $9(23.7)$ & $0(0)$ & $7(25)$ & $3(42.9)$ & $1(33.3)$ & $0(0)$ & ${ }^{\mathrm{c}} .756$ \\
\hline Muscle weakness & $7(18.4)$ & $1(33.3)$ & $5(17.9)$ & $1(14.3)$ & $0(0)$ & $0(0)$ & c.956 \\
\hline Muscle cramps & $7(18.4)$ & $0(0)$ & $8(28.6)$ & $3(42.9)$ & $2(66.7)$ & $0(0)$ & ${ }^{\mathrm{c}} .257$ \\
\hline Numbness & $16(42.1)$ & $2(66.7)$ & $14(50)$ & $4(57.1)$ & $2(66.7)$ & $1(100)$ & ${ }^{\mathrm{c}} .804$ \\
\hline Pain in joints & 7 (18.4) & $0(0)$ & $7(25)$ & $4(57.1)$ & $1(33.3)$ & $0(0)$ & ${ }^{\mathrm{c}} .273$ \\
\hline Elektric shock & $16(42.1)$ & $0(0)$ & $6(21.4)$ & $2(28.6)$ & $0(0)$ & $0(0)$ & c.304 \\
\hline Pinprick & $15(39.5)$ & $1(33.3)$ & $6(21.4)$ & $2(28.6)$ & $1(33.3)$ & $0(0)$ & c. 695 \\
\hline Knife Stabbing & $4(10.5)$ & $0(0)$ & $2(7.1)$ & $2(28.6)$ & $0(0)$ & $0(0)$ & ${ }^{\mathrm{c}} .631$ \\
\hline Hot Flush & $7(18.4)$ & $0(0)$ & $9(32.1)$ & $1(14.3)$ & $0(0)$ & $0(0)$ & ${ }^{\mathrm{c}} .700$ \\
\hline Heat sensivity & $4(10.5)$ & $0(0)$ & $6(21.4)$ & $1(14.3)$ & $0(0)$ & $0(0)$ & c. 789 \\
\hline Cold Sensivity & $24(63.2)$ & $0(0)$ & $8(28.6)$ & $1(14.3)$ & $1(33.3)$ & $0(0)$ & ${ }^{\mathrm{c}} .006$ \\
\hline $\begin{array}{l}\text { Topognosis } \\
\text { (localizing the } \\
\text { sense of touch) }\end{array}$ & $11(28.9)$ & $1(33.3)$ & $10(35.7)$ & $2(28.6)$ & $3(100)$ & $0(0)$ & ${ }^{\mathrm{c}} .225$ \\
\hline
\end{tabular}

Of the 58 patients with neuropathic pain, 13 were determined to get help from another person while dressing, 9 while arising, 10 while eating, 11 while walking, 18 while meeting their hygienic needs, 10 while reaching an object, 20 while gripping or opening an object, and 29 while doing their daily life activities (see Table 3).

As seen in Table 4, the rate of discomfort experienced by patients in their hands and feet (tingling, burning, loss of balance, muscle weakness, muscle cramps, numbness, pain in joints, elektric shock, pinprick, knife stabbing, hot flush, heat sensivity, cold sensivity) as of the onset of chemotherapy administration and their Total HAQ scores were found to be statistically significantly higher $(p=.001 ; p<.01)$.

In the study, while the VAS scores and Total HAQ scores of the group with neuropathic pain were found high, a positive 61.2\% correlation was determined between Total HAQ score and the S-LANSS pain score $(p=.001 ; p<.01, r=0.612)$ (see Table 5).

The comparison of Total HAQ scores by painful symptoms of peripheral neuropathy in hands and feet indicated that the Total HAQ scores of cases with burning were statistically significantly higher $(p=.001 ; p<.01)$ (see Table 6$)$.

\section{Discussion}

This study highlights which neuropathic symptoms are most frequently reported in patients receiving chemotherapy, how patients describe their symptoms, and how these symptoms affect their daily lives. Although chemotherapy drugs are the most commonly used medication in cancer treatment, side effects may develop during treatment. The severity and type of side effects differ from person to person; yet, they may affect the patient's quality of life and cause serious consequences such as discontinuation of treatment, reduction of the treatment dose or termination of treatment. Therefore, this study investigated the relationship of pain associated with peripheral neuropathy in patients receiving chemotherapy with their daily life activities, and the findings obtained were discussed in light of the literature. 
Table 3. Comparison of HAQ scores of the patients experiencing neuropathic pain according to their daily abilities $(n=58)$

\begin{tabular}{|c|c|c|c|}
\hline \multirow{2}{*}{$\begin{array}{l}\text { Daily life activities } \\
\text { - Without any difficulty }(\mathrm{HAQ}=0) \\
\text { - With some diffuculty }(\mathrm{HAQ}=1) \\
\text { - With much difficulty }(\mathrm{HAQ}=\mathbf{2}) \\
\text { - Unable to do }(\mathrm{HAQ}=3)\end{array}$} & \multicolumn{3}{|c|}{ HAQ Scores } \\
\hline & $\mathbf{n}$ & $\begin{array}{l}\text { Min-Max } \\
\text { (Median) }\end{array}$ & $\operatorname{Avg} \pm S D$ \\
\hline \multicolumn{4}{|l|}{ Dress } \\
\hline Without any difficulty & 16 & $0-1.75(0.38)$ & $0.482 \pm 0.539$ \\
\hline With some difficulty & 23 & $0.13-2.5(1.75)$ & $1.507 \pm 0.677$ \\
\hline With much difficulty & 7 & $1.38-2.75(2)$ & $1.929 \pm 0.456$ \\
\hline Unable to do & 12 & $1.25-3(2.38)$ & $2.323 \pm 0.496$ \\
\hline \multicolumn{4}{|l|}{ Arise } \\
\hline Without any difficulty & 22 & $0-2.13(0.5)$ & $0.652 \pm 0.66$ \\
\hline With some difficulty & 22 & $0.28-2.25(1.75)$ & $1.694 \pm 0.499$ \\
\hline With much difficulty & 10 & $0.88-2.88(2.31)$ & $2.175 \pm 0.641$ \\
\hline Unable to do & 4 & $2.25-3(2.56)$ & $2.594 \pm 0.313$ \\
\hline \multicolumn{4}{|l|}{ Eating } \\
\hline Without any difficulty & 16 & $0-2.63(0.67)$ & $0.685 \pm 0.781$ \\
\hline With some difficulty & 23 & $0.25-2.5(1.38)$ & $1.267 \pm 0.646$ \\
\hline With much difficulty & 7 & $1.88-2.25(2.13)$ & $2.107 \pm 0.134$ \\
\hline Unable to do & 12 & $1.75-3(2.38)$ & $2.406 \pm 0.385$ \\
\hline \multicolumn{4}{|l|}{ Walking } \\
\hline Without any difficulty & 16 & $0-2.25(0.31)$ & $0.570 \pm 0.735$ \\
\hline With some difficulty & 19 & $0.28-2.13(1.38)$ & $1.263 \pm 0.528$ \\
\hline With much difficulty & 9 & $0.75-2.5(2)$ & $1.903 \pm 0.483$ \\
\hline Unable to do & 14 & $1.75-3(2.38)$ & $2.393 \pm 0.379$ \\
\hline \multicolumn{4}{|l|}{ Hygiene } \\
\hline Without any difficulty & 15 & $0-1.13(0.28)$ & $0.318 \pm 0.359$ \\
\hline With some difficulty & 9 & $0.25-1.75(1.13)$ & $1.038 \pm 0.449$ \\
\hline With much difficulty & 12 & $0.75-2.75(1.88)$ & $1.833 \pm 0.507$ \\
\hline Unable to do & 22 & $1.38-3(2.19)$ & $2.165 \pm 0.447$ \\
\hline \multicolumn{4}{|l|}{ Reach } \\
\hline Without any difficulty & 15 & $0-1.25(0.25)$ & $0.291 \pm 0.355$ \\
\hline With some difficulty & 17 & $0.63-2.25(1.5)$ & $1.515 \pm 0.508$ \\
\hline With much difficulty & 11 & $0.75-2.5(2)$ & $1.932 \pm 0.489$ \\
\hline Unable to do & 15 & $0.88-3(2.25)$ & $2.158 \pm 0.633$ \\
\hline \multicolumn{4}{|l|}{ Grip } \\
\hline Without any difficulty & 15 & $0-2(0.25)$ & $0.433 \pm 0.553$ \\
\hline With some difficulty & 12 & $0.28-2(1.13)$ & $1.041 \pm 0.548$ \\
\hline With much difficulty & 13 & $1.13-2.5(1.75)$ & $1.865 \pm 0.446$ \\
\hline Unable to do & 18 & $1.5-3(2.13)$ & $2.250 \pm 0.416$ \\
\hline \multicolumn{4}{|l|}{ Activities } \\
\hline Without any difficulty & 10 & $0-0.75(0)$ & $0.150 \pm 0.249$ \\
\hline With some difficulty & 6 & $0.38-1.75(1)$ & $0.979 \pm 0.550$ \\
\hline With much difficulty & 11 & $0.28-2.5(1.63)$ & $1.476 \pm 0.724$ \\
\hline Unable to do & 31 & $0.63-3(2)$ & $1.940 \pm 0.611$ \\
\hline
\end{tabular}


Table 4. Comparison of patients' neuropathic pain and total HAQ scores experiencing discomfort in hands and feet as of the onset of chemotherapy administration

\begin{tabular}{|c|c|c|c|c|}
\hline & Neuropathic pain $(+)(\mathbf{n}=58)$ & Neurop: & thic pain $(-)(n=22)$ & $p$ \\
\hline \multicolumn{5}{|c|}{$\begin{array}{l}\text { The rate of discomfort experienced by } \\
\text { patients in their hands and feet as of the } \\
\text { onset of chemotherapy administration }\end{array}$} \\
\hline Yes & $48(82.8)$ & \multicolumn{2}{|r|}{$10(45.5)$} & b $.001^{* *}$ \\
\hline \multirow[t]{3}{*}{ No } & $10(17.2)$ & & $12(54.5)$ & \\
\hline & \multicolumn{3}{|c|}{ Total HAQ Scores } & \\
\hline & $\mathbf{N}$ & Min-Max & $\operatorname{Avg} \pm S D$ & $p$ \\
\hline \multicolumn{5}{|c|}{$\begin{array}{l}\text { The rate of discomfort experienced by } \\
\text { patients in their hands and feet as of the } \\
\text { onset of chemotherapy administration }\end{array}$} \\
\hline Yes & 58 & $0-3(1.63)$ & $1.455 \pm 0.901$ & ${ }^{\mathrm{d}} .001^{* *}$ \\
\hline No & 22 & $-2.25(0.44)$ & $0.648 \pm 0.715$ & \\
\hline
\end{tabular}

Note. ${ }^{* *} p<.01 ;{ }^{\mathrm{b}}$ Pearson Chi-Square Test; ${ }^{\mathrm{d}}$ Mann Whitney $U$ Test

Table 5. Comparison of pain and total HAQ scores of the patients experiencing neuropathic pain

\begin{tabular}{lccc}
\hline & Neuropathic pain $(+)(\mathbf{n = 5 8})$ & Neuropathic pain $(-)(\mathbf{n = 2 2})$ & $\boldsymbol{p}$ \\
\hline Total HAQ & & & \\
$\quad$ Min-Max (Median) & $0-3(1.7)$ & $0-2.9(0.3)$ & ${ }^{\mathrm{d}} .001^{* *}$ \\
Avg $\pm S D$ & $1.44 \pm 0.88$ & $0.68 \pm 0.81$ & \\
VAS (Visual Analog Scale) & $0-10(6)$ & $0-10(1)$ & ${ }^{\mathrm{d}} .001^{* *}$ \\
$\quad$ Min-Max (Median) & $5.76 \pm 2.89$ & $2.14 \pm 2.83$ & \\
Avg $\pm S D$ & &
\end{tabular}

Note. ${ }^{* *} p<.01 ;{ }^{\mathrm{d}}$ Mann Whitney $U$ Test

The results of this study revealed that the most frequent symptoms observed in the patients according to the class of drugs were sensitivity to cold (63.2\%) and tingling (52.6\%) in patients using platinum; the most numbness in patients using platinum + vinca $(66.7 \%)$; the most numbness $(50 \%)$, tingling $(46.4 \%)$, and burning $(42.9 \%)$ in patients using taxane; pain in joints $(57.1 \%)$ and numbness $(57.1 \%)$ in patients using taxane + platinum; reduced sensitivity $(100 \%)$ in patients using vinca. On the other hand, Tofthagen (2011) determined that the most common symptoms in patients receiving oxaliplatin were cold sensitivity (84.8\%), tingling in hands $(66.6 \%)$ and reduced sensitivity $(54.5 \%)$. In the study of Kirömeroğlu ${ }^{[20]}$ neuropathic symptoms were mostly observed in platinum drug groups, and the most common ones were weakness, pain in joints, muscular cramps, discomfort in hands, and numbness and tingling in hands. Besides, in the study of Boru et al., ${ }^{[23]}$ neurotoxicity was observed to increase in weekly intake of paclitaxel. According to these results, cancer drugs were observed to cause a high rate of polyneuropathy.

In the study, neuropathic pain was observed in $72.5 \%(\mathrm{n}=$ Published by Sciedu Press
58) of the patients. When the definition of the discomfort in these patients' hands and feet was examined, they were observed to respond using phrases such as numbness, burning, electric-shock-like pain, chills, fatigue, reduced sensitivity, and tingling. Also, the word "pain" was used by only $8.8 \%$ $(n=7)$. In the study conducted by Tofthagen in $2010,50 \%$ of patients $(n=14)$ had pain characterized by neuropathic pain, and they described this pain as an electric-shock like pain, stabbing, or sharp pain. Also, 10 patients used the word "pain" when describing the painful symptoms they experienced, while 4 of them did not use it at all. Accordingly, it is noteworthy that patients with neuropathic pain did not use the word "pain" to describe the discomfort they experienced. In this study, the patients responded "yes" to the question "Do you experience any discomfort in your hands and feet?", and they marked the painful symptoms of peripheral neuropathy; however, they gave 0 points in the assessment of the neuropathic pain score. This suggested that either the patients did not accept that they had pain or they experienced sensory loss as a result of advanced neuropathy, and therefore the level of feeling pain decreased. 
Table 6. Comparison of total HAQ scores according to painful and painless symptoms of peripheral neuropathy in hands and feet $(\mathrm{n}=80)$

\begin{tabular}{|c|c|c|c|c|}
\hline \multirow{2}{*}{$\begin{array}{l}\text { Painful symptoms of peripheral } \\
\text { neuropathy in hands and feet }\end{array}$} & \multicolumn{3}{|c|}{ Total HAQ Scores } & \multirow{2}{*}{${ }^{\mathrm{d}} p$} \\
\hline & $\mathbf{n}$ & Min-Max (Median) & $\operatorname{Avg} \pm S D$ & \\
\hline \multicolumn{5}{|l|}{ Burning } \\
\hline Yes & 25 & $0.13-3(2)$ & $1.775 \pm 0.846$ & \multirow{2}{*}{$.001^{* * *}$} \\
\hline No & 55 & $0-2.88(0.88)$ & $0.986 \pm 0.855$ & \\
\hline \multicolumn{5}{|l|}{ Muscle cramps } \\
\hline Yes & 20 & $0-2.75(1.44)$ & $1.248 \pm 0.816$ & \multirow{2}{*}{.933} \\
\hline No & 60 & $0-3(1.19)$ & $1.228 \pm 0.963$ & \\
\hline \multicolumn{5}{|l|}{ Pain of joints } \\
\hline Yes & 19 & $0-3(1.63)$ & $1.388 \pm 0.915$ & \multirow{2}{*}{.410} \\
\hline No & 61 & $0-2.88(1.13)$ & $1.184 \pm 0.928$ & \\
\hline \multicolumn{5}{|l|}{ Elektrical shocks } \\
\hline Yes & 24 & $0-2.88(0.81)$ & $1.161 \pm 1.022$ & \multirow{2}{*}{.732} \\
\hline No & 56 & $0-3(1.31)$ & $1.263 \pm 0.886$ & \\
\hline \multicolumn{5}{|l|}{ PinPrick } \\
\hline Yes & 25 & $0-3(1.75)$ & $1.570 \pm 0.913$ & \multirow{2}{*}{$.030^{*}$} \\
\hline No & 55 & $0-2.88(1.13)$ & $1.079 \pm 0.895$ & \\
\hline \multicolumn{5}{|l|}{ Knife Stabbing } \\
\hline Yes & 8 & $0.25-3(1.19)$ & $1.347 \pm 1.007$ & \multirow{2}{*}{.658} \\
\hline No & 72 & $0-2.88(1.25)$ & $1.220 \pm 0.921$ & \\
\hline \multicolumn{5}{|l|}{ Hot Flush } \\
\hline Yes & 17 & $0-3(0.88)$ & $1.134 \pm 0.941$ & \multirow{2}{*}{.705} \\
\hline No & 63 & $0-2.88(1.38)$ & $1.259 \pm 0.925$ & \\
\hline \multicolumn{5}{|l|}{ Heat Sensivity } \\
\hline Yes & 11 & $0-3(0.88)$ & $1.195 \pm 1.055$ & \multirow{2}{*}{.922} \\
\hline No & 69 & $0-2.88(1.38)$ & $1.239 \pm 0.909$ & \\
\hline \multicolumn{5}{|l|}{ Cold Sensivity } \\
\hline Yes & 34 & $0-3(1.19)$ & $1.221 \pm 0.999$ & \multirow{2}{*}{.934} \\
\hline No & 46 & $0-2.88(1.31)$ & $1.241 \pm 0.875$ & \\
\hline \multicolumn{5}{|c|}{ Painless symptoms of peripheral neuropathy in hands and feet } \\
\hline \multicolumn{5}{|c|}{ Tingling } \\
\hline Yes & 37 & $0-3(1.38)$ & $1.243 \pm 0.941$ & \multirow{2}{*}{.900} \\
\hline No & 43 & $0-2.88(1.25)$ & $1.224 \pm 0.920$ & \\
\hline Loss of balance & & & & \\
\hline Yes & 20 & $0-3(1.69)$ & $1.439 \pm 0.924$ & \\
\hline No & 60 & $0-2.88(1.19)$ & $1.164 \pm 0.921$ & .239 \\
\hline Muscle weakness & & & & \\
\hline Yes & 14 & $0-3(1.81)$ & $1.616 \pm 0.959$ & \\
\hline No & 66 & $0-2.88(1.13)$ & $1.151 \pm 0.902$ & .092 \\
\hline Numbness & & & & \\
\hline Yes & 39 & $0-3(1.63)$ & $1.486 \pm 0.886$ & $015^{*}$ \\
\hline No & 41 & $0-2.75(0.88)$ & $0.991 \pm 0.904$ & .015 \\
\hline Topognosis & & & & \\
\hline Yes & 27 & $0-3(1.38)$ & $1.342 \pm 0.946$ & \\
\hline No & 53 & $0-2.88(1.25)$ & $1.177 \pm 0.916$ & .420 \\
\hline
\end{tabular}

Note. ${ }^{\mathrm{d}}$ Mann Whitney $U$ Test $;{ }^{*} p<.05 ;{ }^{* *} p<.01$

Shahidi et al. ${ }^{[22]}$ reported that as a result of a cancer diagnosis or cancer treatment, there were changes in patients' daily life activities such as sleeping or taking a nap during the day, do- ing housework, doing exercises, doing sports, watching TV, doing nothing at all, and visiting relatives. On the other hand, Tofthagen stated that patients had difficulty in performing ac- 
tivities such as doing hobbies, sleeping, exercising, walking, gripping objects, doing housework, writing, dressing, and driving. ${ }^{[12]}$ This study also found that cancer patients had difficulties in doing their daily life activities (gripping and opening things, meeting hygienic needs, dressing, walking, eating, reaching an object, and raising).

In the present study, the comparison of Total HAQ scores and S-LANSS scores in terms of the number of cures yielded no statistically significant difference. However, Total HAQ scores of patients who received chemotherapy more than three cures were observed to be higher. In the study of Ustundag, the physical well-being of the patient group receiving taxane was not affected, yet the HAQ scores of the group using taxane in this study were found high. ${ }^{[26]}$ This may have stemmed from the fact that the number of patients in this study, receiving only platinum and only taxane group drugs was high and that increased neurotoxicity due to weekly intake of paclitaxel drug augmented Total HAQ score.

In the study, the comparison of Total HAQ score and SLANSS pain score indicated that there was a statistically significant and positive relationship at a level of $61.2 \%$ ( $\mathrm{r}$ $=0.612 ; p=0.001 ; p<0.01)$. On the other hand, VAS and Total HAQ scores of the group with neuropathic pain were also significantly higher $(\mathrm{p}=0.001 ; \mathrm{p}<0.01)$. In the MIND Study (The study that compares peripheral and autonomic neuropathy with S-LANNS, HAQ and VAS scales in type 2 diabetes) conducted by Syngle et al., ${ }^{[25]}$ both LANSS and Total HAQ scores of patients were determined to decrease after the drug called minocycline, while an improvement was obtained in VAS scale. With this respect, the data of the S-LANSS, Total HAQ, and VAS scales of the present study were similar to those of the MIND study.

In our study, patients with a feeling of "burning" and "nee-

\section{REFERENCES}

[1] Sira F. Evaluate of symptoms in oncology patients receiving chemotherapy. Marmara University Institute of Health Sciences, Master's Thesis, Istanbul; 2007.

[2] Korkmaz O. Evaluation of nursing intervention while managing chemotherapy reactions. Istanbul University Institute of Health Sciences, Doctoral Thesis, Istanbul; 2008. Available from: http: //nek. istanbul.edu.tr:4444/ekos/TEZ/43474.pdf

[3] Aslan O. Assessing the chemotherapy symptoms and determining the effect of nursing education role on cancer patients undergoing chemotherapy. Gulhane Military Medicine Academy Institute of Health Sciences, Master's Thesis, Ankara; 2003.

[4] Ates S, Olgun N. Chemotherapy Induced Alopecia and Quality of Life. Journal of Hacettepe University Faculty of Nursing. 2014; 67- dles", which are painful symptoms of peripheral neuropathy, and "numbness", which is one of the painless symptoms, were found to have high Total scores (see Table 6). In the study of Tofthagen and Mcmillan, the physical and mental component scores of patients with numbness, tingling, electrick-shock-like pain, and high level of pain were observed to be lower, and they had more difficulty performing their daily life activities. ${ }^{[24]}$ In this context, the data obtained in the study of Tofthagen and Mcmillan were similar to those of the current study.

\section{Conclusions}

Peripheral neuropathy related-factors and pain affect patients' ability to perform their daily activities independently. Patients with neuropathic pain have difficulty in performing daily activities and many patients carry out these activities with help either from another person or ancillary equipment. Making a very good and systematic assessment of the pain and pain-related factors that affect patients' performance of daily activities and are associated with peripheral neuropathy will help to increase patients' independence while doing their daily activities. Nurses, who have very much interaction with patients, can timely notice and do a systematic assessment of the symptoms developing in patients who get help from another person or have difficulty performing daily life activities, and they can plan and implement the appropriate nursing interventions, which will, in turn, reduce the physical dependence of the patient.

\section{LIMITATIONS OF THE STUDY}

The fact that the study was conducted in a single hospital was accepted as the limitation of the study.

\section{CONFLICTS OF INTEREST Disclosure}

The authors declare they have no conflicts of interest.
80. Available from: https://dergipark.org.tr/tr/download /article-file/88631

[5] Imdat D. Evaluate of Toxicity in Chemotherapy. XXXVI. National Hemotology Congress, Antalya. 2010. Available from: http://www.thd.org.tr/thdData/Books/332/kemoterap ide-toksisite-degerlendirmesi-imdat-dilek.pdf

[6] Can G. Evidence-Based Symptom Management in Oncology Nursing. Yildirim Y. Neurotoxicity. 2010; 159-172. Available from: https: //www.researchgate.net/publication/236903162_Onkol oji_Hemsireliginde_Kanita_Dayali_Semptom_Yonetimi

[7] Wickham R. Chemotherapy-induced peripheral neuropathy: a review and implications for oncology nursing practice. Clin J Oncol Nurs. 2007; 11(3): 361-76. PMid: 17623621. https://doi.org/10.1 188/07. CJON.361-376 
[8] Yarbro CH, Frogge MH, Goodman M, et al. Cancer Nursing: Principles and Practice, Fifth Edition, Jonesadn Barlett Publishers; 2005. Available from: https://www.cancernetwork.com/view/can cer-nursing-principles-and-practice-5th-edition

[9] Perry MC, Hausheer FH. Chemotherapy Induced Peripheral Neuropathy. The Chemotherapy Source Book, (4. bask1). Philadelphia: Lippincott Williams \& Wilkins; 2008. 234- 244 p.

[10] Tan M, Sahin Z. Search of the Condition Satisfaction of Nursing Care in Chemotherapy Patients. Journal of Atatürk University Faculty of Nursing. 2009; 12(3). Available from: https://atif . sobiad.com/index.jsp?modul=makale-det ay\&Alan=tip\&Id=AV492h6xDohDRoFDjFzS

[11] Reyes-Gibby CC, Morrow PK, Buzdar A, et al. ChemotherapyInduced Peripheral Neuropathy as a Predictor of Neuropathic Pain in Breast Cancer Patients Previously Treated With Paclitaxel. J Pain. 2009; 10: 11. PMid: 19595634. https://doi.org/10.1016/j. jpain. 2009.04.006

[12] Tofthagen C. Patient Perception Assosiated with ChemotherapyInduced Peripheral Neuropathy. Clin J Oncol Nurs. 2010; 14: 3. PMid: 20529785. https://doi.org/10.1188/10.CJON.E22-E 28

[13] Tofthagen C, McAllister RD, McMillan SC. Peripheral Neuropathy in Patients with Colorectal Cancer Receiving Oxaliplatin. Clin J Oncol Nurs. 2011; 15: 2. PMid: 21444285. https://doi.org/10.1188/11.CJON.182-188

[14] Lavoie SE, Bakitas WM, Bookbinder M. Quality Improvement of Painful Peripheral Neuropathy. Semin Oncol Nurs. 2002; 38(1): 3643. PMid: 11878038. https://doi.org/10.1053/sonu. 2002 . 30043

[15] Kaley TJ, DeAngelis LM. Therapy of Chemotheraphy- Induced Peripheral Neuropathy. Br Jhaematol. 2009; 145: 3-14. PMid: 19170681. https://doi.org/10.1111/j.1365-2141.2008.0 7558. $\mathrm{x}$

[16] Bennett MI, Smith BH, Torrance N, et al. The S-LANSS score for identifying pain of predominantly neuropathic origin: validation for use in clinical and postal research. J Pain. 2005; 6: 149158. PMid: 15772908. https ://doi.org/10.1016/j.jpain. 20 04.11 .007

[17] Koc R, Erdemoglu AK. Validity and reliability of the Turkish Selfadministered Leeds Assessment of Neuropathic Symptoms and Signs (S-LANSS) Questionnaire. Pain Med. 2010; 11(7): 1107-1114. PMid:
20456071. https://doi.org/10.1111/j.1526-4637.2010.0 $0837 . \mathrm{x}$

[18] Bruce B, Fries JF. The Stanford Health Assessment Questionnaire: A review of its history, issues, progress, and documentation. Journal of Rheumatology. 2003; 30(1): 167-78.

[19] Kucukdeveci AA, Sahin H, Ataman S, et al. İssues in cross cultural validity: example from the adaptation, reliability and validity testing of a Turkish version of the Standford Health Assessment Questionnaire. Arthritis Care Res. 2004; 51(1): 14-9. PMid: 14872450. https://doi.org/10.1002/art. 20091

[20] Kiromeroglu Saraydemir S. Assesment of Neuropathic Conditions in Chemotherapy Patients. Acibadem University Institute of Health Sciences, Master's Thesis, Istanbul; 2012.

[21] Sadirli KS. Assessment of Symptom Control Patients with Cancer. Trakya University Institute of Health Sciences. Master's Thesis, Edirne; 2008.

[22] Shahidi J, Taghizadeh-Kermani A, Gohari MR, et al. Changes in daily activities of cancer patients after diagnosis: How do Canadian and İranian patients perceive the change? Iranian Journal of Cancer Prevention. 2014; 7(1). Available from: https://www.ncbi.nlm .nih.gov/pmc/articles/PMC4142954/

[23] Boru TU, Cemberci C, Padir N, et al. Chemotherapy Induced Toxic Polyneuropathy in Cancer Patients. The Medical Journal of Okmeydanı Training and Research Hospital. 2016; 32(2): 69-74. Available from: http: //www . okmeydanitipdergisi.org/jvi.asp? pdir=eamr\&plng=tur\&volume=32\&issue $=2$

[24] Tofthagen C, McMillan, SC. Pain, neuropathic symptoms, and physical and mental well-being persons with cancer. Cancer Nurs. 2010; 33: 437-444. PMid: 21479139. https://doi .org/10.1097/NCC. Ob013e3181e212b4

[25] Syngle A, Verma I, Krishan P, et al. Minocycline improves peripheral and autonomic neuropathy in type 2 diabetes : MIND study.Neurol Scil. 2014; 35(7): 1967-73. PMid: 24497205. https : //doi.org/10.1007/s10072-014-1647-2

[26] Ustundag S. The Effect of Complementary Therapy for Symptoms Management on Life Quality of Chemothrapy Taking Cancer Patients. Ankara University Institute of Health Sciences,Master's Thesis, Ankara; 2013. Available from: https ://dspace. ankara.edu.tr/xmlui/bitstream/handl e/20.500.12575/32592/tez.pdf?sequence=1 